\title{
Vibration mitigation of stay cable using optimally tuned MR damper
}

\author{
Hongwei Huang*1, Limin Sun ${ }^{2}$ and Xiaolu Jiang ${ }^{3}$ \\ ${ }^{1}$ State Key Laboratory for Disaster Reduction in Civil Engineering, \\ Tongji University, Shanghai, China \\ ${ }^{2}$ Department of Bridge Engineering, Tongji University, Shanghai, China \\ ${ }^{3}$ Shanghai Urban Construction Design \& Research Institute, Shanghai, China \\ (Received December 19, 2010, Revised May 26, 2011, Accepted November 30, 2011)
}

\begin{abstract}
Mechanical dampers have been proved to be one of the most effective countermeasures for vibration mitigation of stay cables in various cable-stayed bridges over the world. However, for long stay cables, as the installation height of the damper is restricted due to the aesthetic concern, using passive dampers alone may not satisfy the control requirement of the stay cables. In this connection, semi-active MR dampers have been proposed for the vibration mitigation of long stay cables. Although various studies have been carried out on the implementation of MR dampers on stay cables, the optimal damping performance of the cable-MR damper system has yet to be evaluated. Therefore, this paper aims to investigate the effectiveness of MR damper as a semi-active control device for the vibration mitigation of stay cable. The mathematical model of the MR damper will first be established through a performance test. Then, an efficient semi-active control strategy will be derived, where the damping of MR damper will be tuned according to the dynamic characteristics of stay cable, in order to achieve optimal damping of cable-damper system. Simulation study will be carried out to verify the proposed semi-active control algorithm for suppressing the cable vibrations induced by different loading patterns using optimally tuned MR damper. Finally, the effectiveness of MR damper in mitigating multi modes of cable vibration will be examined theoretically
\end{abstract}

Keywords: long stay cable; vibration mitigation; MR damper; semi-active control; performance evaluation.

\section{Introduction}

With the application of new materials and new construction technologies, the main span of cablestayed bridge increases significantly and has exceeded $1000 \mathrm{~m}$. As the main force-bearing components in cable-stayed bridges, the length of stay cables increase as well. Thus, using passive dampers alone may not satisfy the control requirement of the stay cables. In this connection, semiactive MR dampers have been proposed for the vibration mitigation of long stay cables for the advantage of lower energy consumption, adjustable input and wide control range. $\mathrm{Wu}$ and Cai (2006) carried out performance test on MR damper and studied the effect of input current, frequency, type of excitations and temperature on damper behavior, and they also conducted the scaled cable vibration tests and found that MR damper is effective for mitigating cable vibrations. Liu et al. (2006) conducted series of scaled cable vibration tests to verify the control effectiveness

*Corresponding author, Associate professor, E-mail: hongweih@tongji.edu.cn 
of semi-active MR damper as compared to the passive dampers. Weber et al. (2007a, 2007b, 2007c) applied the energy equivalent approach to model MR damper as equivalent linear viscous damper or nonlinear friction damper in the theoretical and experimental studies of cable vibration control using MR dampers. Besides theoretical work and lab testing, MR dampers have also been applied to real bridge projects, such as the Eiland bridge nearby Kampen, The Netherlands (Weber et al. (2005)), the Dongting Lake Bridge (Chen et al. (2001), Wang et al. (2003), Duan et al. (2006)), Third Qiantang River Bridge (Wu et al. (2004)), Bingzhou Yellow River Highway Bridge (Li et al. (2007)) and Sutong Bridge in China.

Although various theoretical and experimental studies have been carried out on the implementation of MR dampers on stay cables, the unique dynamic characteristic of cable vibration has not been fully taken into consideration in the derivation of control algorithms, and the optimal damping performance of the cable-MR damper system has yet to be evaluated. Also, the mathematical model of MR damper developed so far appears to be too complex when incorporated into the control system of stay cable, and therefore, most of the bridges are installed with MR dampers in a passive-on mode without the application of semi-active control algorithm. In this connection, a simple relation between the damping parameters of MR damper and the input current has to be established, in order for the derivation of semi-active control algorithms for stay cable using MR damper.

Therefore, this paper aims to study the optimal damping performance of the cable-MR damper system and to investigate the effectiveness of the MR damper as a semi-active control device for the vibration mitigation of stay cable. The mathematical model of the MR damper will first be studied through a performance test, and the relation between the damping parameters and the input current will be established. Then, an efficient semi-active control strategy will be derived, where the damping of MR damper will be tuned according to the dynamic characteristics of stay cable, in order to achieve optimal damping of cable-damper system. Simulation study will be carried out to verify the proposed semi-active control algorithm for suppressing the cable vibrations induced by different loading patterns using optimally tuned MR damper. Finally, the effectiveness of MR damper in mitigating multi modes of cable vibration will be examined theoretically.

The MR damper under consideration in this paper is RD-1005-03 developed by the LORD Corporation, which is a popular damper in civil engineering practice.

\section{Performance test of MR damper}

A performance test was first carried out to verify the mathematical model of the MR damper, where the relationships between the equivalent damping of the MR damper and the input current was established. This mathematical model will be used in the derivation of semi-active control algorithm in the following session.

\subsection{Experimental set up}

The MR damper, RD-1005-03, developed by the LORD Corporation was used, and the test was performed on the MTS material testing machine in the Mechanical Lab of Shanghai Jiao Tong University.

The external excitation was input in the form of displacement, i.e., 
Table 1 Test scenarios for MR dampers $(\mathrm{I}=0 \mathrm{~A}, 0.5 \mathrm{~A}, 1 \mathrm{~A}, 1.5 \mathrm{~A}, 2 \mathrm{~A})$

\begin{tabular}{|c|c|c|c|c|c|}
\hline Freq $A m p$ & $0.5 \mathrm{~mm}$ & $1 \mathrm{~mm}$ & $2 \mathrm{~mm}$ & $5 \mathrm{~mm}$ & $10 \mathrm{~mm}$ \\
\hline $0.6 \mathrm{~Hz}$ & $\bullet$ & $\bullet$ & $\bullet$ & $\bullet$ & $\bullet$ \\
\hline $1.3 \mathrm{~Hz}$ & • & $\bullet$ & • & - & \\
\hline $2 \mathrm{~Hz}$ & $\bullet$ & $\bullet$ & $\bullet$ & • & \\
\hline $3 \mathrm{~Hz}$ & - & $\bullet$ & $\bullet$ & & \\
\hline $4 \mathrm{~Hz}$ & • & $\bullet$ & • & & \\
\hline $5 \mathrm{~Hz}$ & • & $\bullet$ & & & \\
\hline $6 \mathrm{~Hz}$ & • & $\bullet$ & & & \\
\hline $7 \mathrm{~Hz}$ & $\bullet$ & $\bullet$ & & & \\
\hline
\end{tabular}

where $\bullet$ indicates test scenarios.

$$
u=A \sin (2 \pi f t)
$$

where the amplitude and frequency are changed for different loading cases, and the input current for MR damper also varies under each loading pattern. The damper forces and displacement are measured for more than 40 cycles with sampling frequency higher than $1000 \mathrm{~Hz}$. Due to the limitation of the test machine, the maximum input velocity can be achieved is $f . A<10 \mathrm{~mm} / \mathrm{s}$.

The test scenarios are summarized in Table 1 . The force-displacement and force-velocity hysteresis loops of the MR damper are plotted in Figs. 1-2 for one of the test scenarios as representation. It can be seen that when the input current of MR damper increases from 0 to the maximum working current of $2 \mathrm{~A}$, the area of hysteresis loop first increases significantly, then the rate of increment begins to slow down when the input current exceeds $0.5 \mathrm{~A}$, which indicates the nonlinear damping behavior of MR damper with changes of input current.

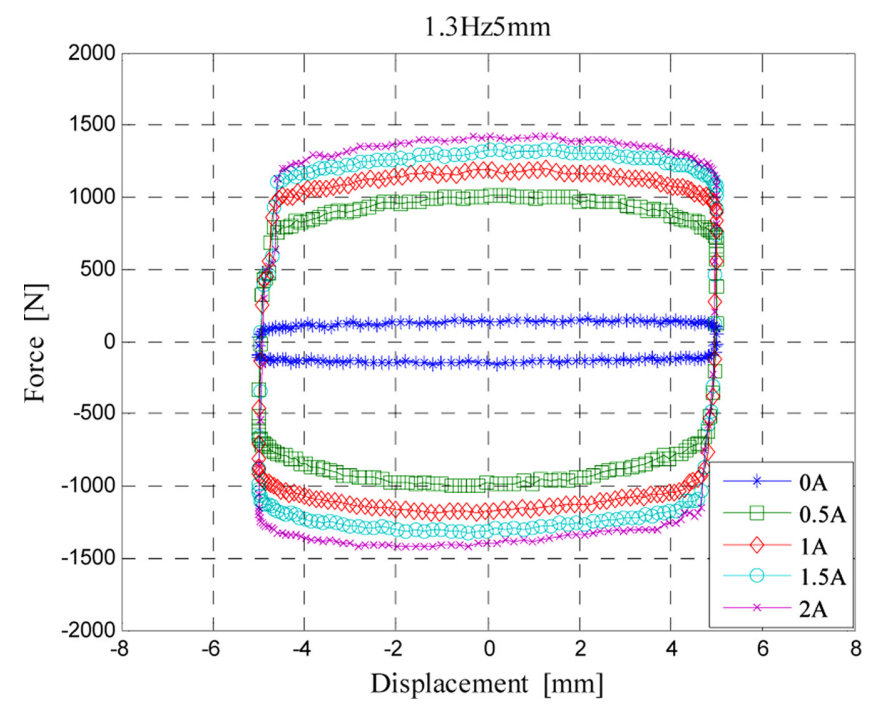

Fig. 1 Force-displacement hysteresis loop $(1.3 \mathrm{~Hz}, 5 \mathrm{~mm})$ 


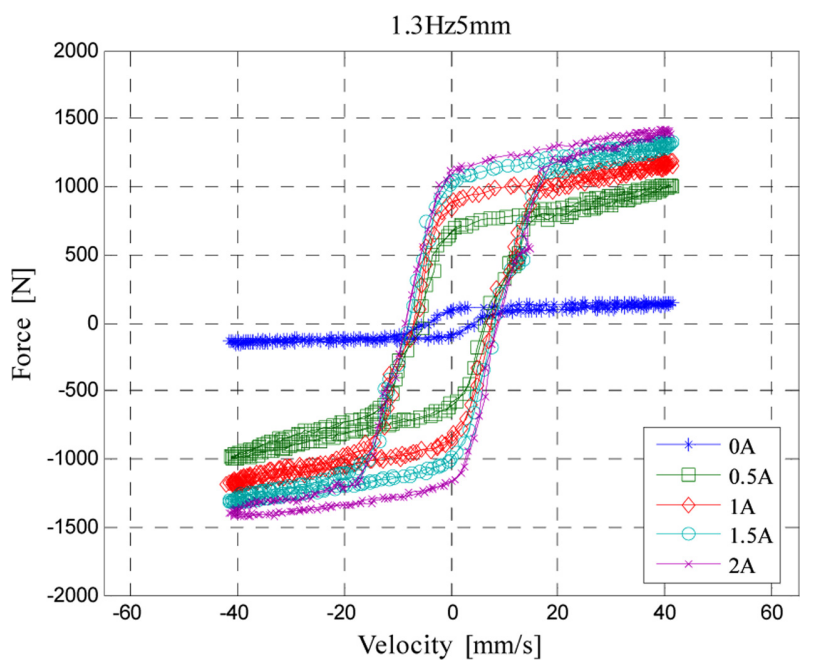

Fig. 2 Force-velocity hysteresis loop $(1.3 \mathrm{~Hz}, 5 \mathrm{~mm})$

\subsection{Equivalent damping}

In the optimal design of stay cable with dampers, the maximum additional damping achieved by the cable-damper system is determined using the universal curve which bases on linear damper theory. Hence, in order to use the same universal curve for the optimal design of cable-MR damper system, the linearly equivalent damping of MR damper is considered. The equivalent damping of MR damper can be computed based on the energy dissipation of the damper under each cycle of hysteresis loop. The energy dissipation of every hysteresis loop can be calculated using the following equation

$$
\Delta E=\int_{t}^{t+\tau} F_{d} \dot{w}_{d} d t
$$

where $F_{d}$ is the damping force, and $\dot{w}_{d}$ is the damper velocity.

Then the equivalent damping of the damper can be obtained as

$$
c_{e q}=\Delta E \frac{\tau}{2 \pi^{2} W_{d}^{2}}
$$

where $W_{d}$ is the magnitude of vibration, and $\tau$ is the period.

\subsection{Parametric identification}

The equivalent damping of the MR damper for each testing case is obtained using the above equations. The relation between the equivalent damping and the input current is plotted in Fig. 3 with selected test cases, and the relation between the equivalent damping and the maximum damper velocity is presented in Fig. 4. It can be seen from the figures that the equivalent damping has a bilinear relation with the input current for the same damper velocity, and has a nonlinear relation with 


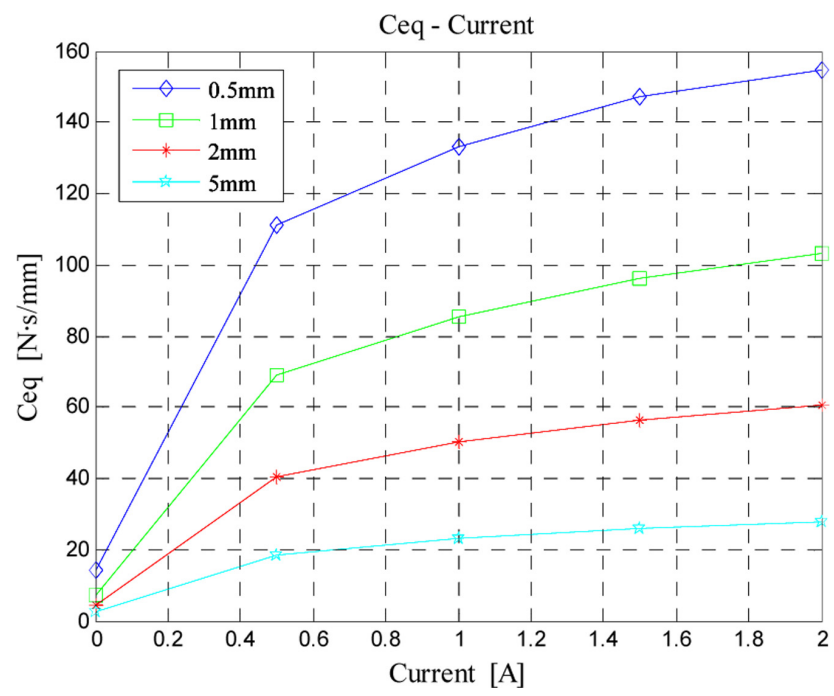

Fig. 3 Equivalent damping vs input current

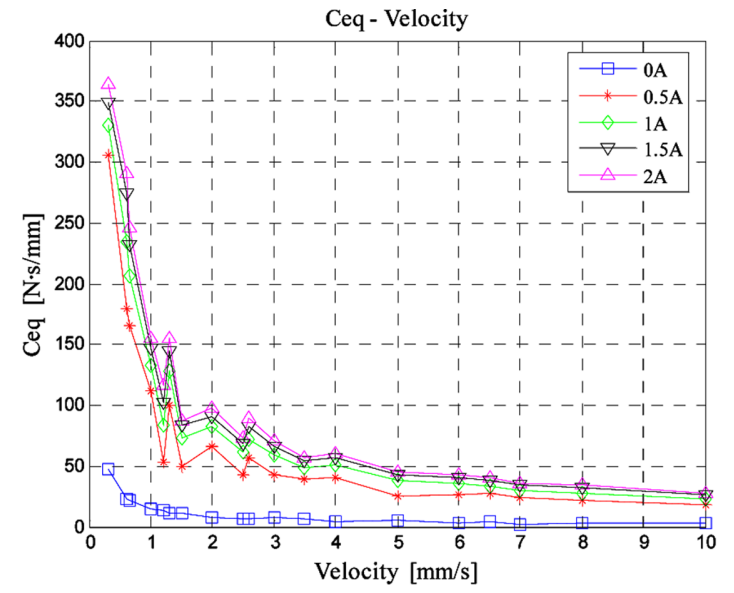

(a) Test results

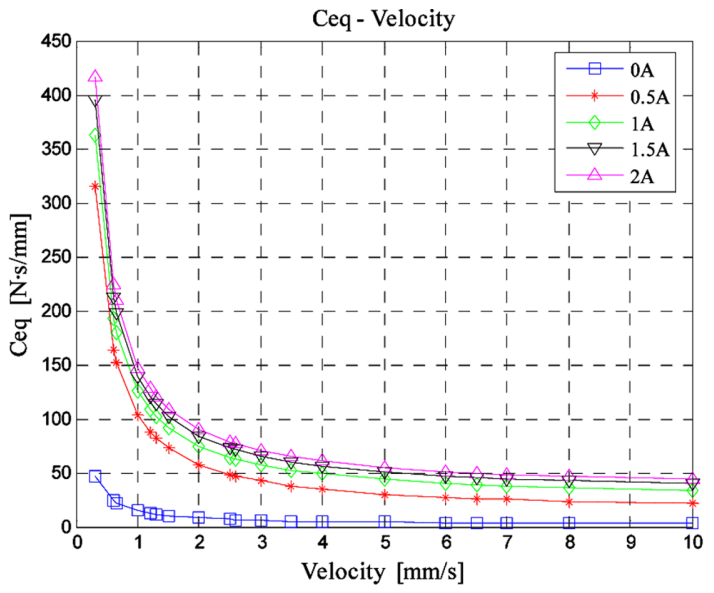

(b) Curve fitting

Fig. 4 Equivalent damping vs maximum damper velocity

the maximum damper velocity with certain input current. These relations can be summarized and represented using the following equations after curve fitting.

$$
\begin{gathered}
C=C_{e}+\frac{F_{e}}{V_{\max }} \\
C_{e}=\left\{\begin{array}{cc}
c_{1} I+c_{2} & 0 \leq I \leq 0.5 \mathrm{~A} \\
c_{3} I+c_{4} & 0.5 \mathrm{~A} \leq I \leq 2 \mathrm{~A}
\end{array}\right. \\
F_{e}=\left\{\begin{array}{cc}
f_{1} I+f_{2} & 0 \leq I \leq 0.5 \mathrm{~A} \\
f_{3} I+f_{4} & 0.5 \mathrm{~A} \leq \mathrm{I} \leq 2 \mathrm{~A}
\end{array}\right.
\end{gathered}
$$




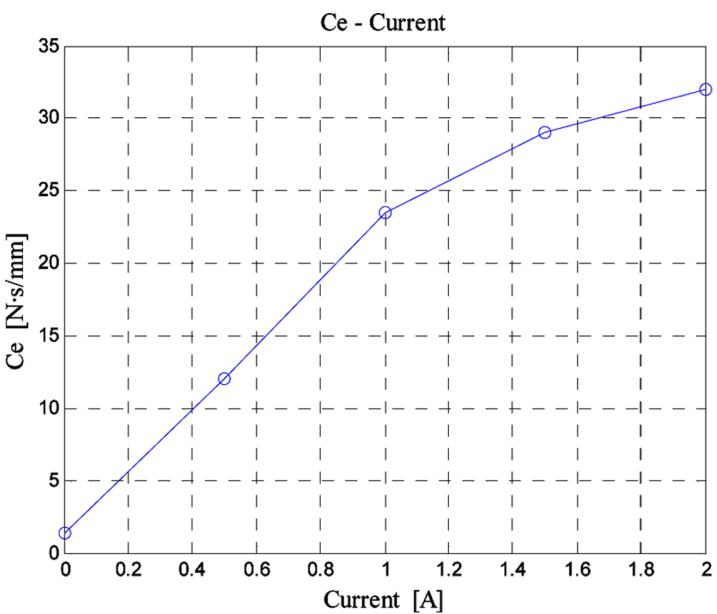

(a) $C_{e}$ vs current

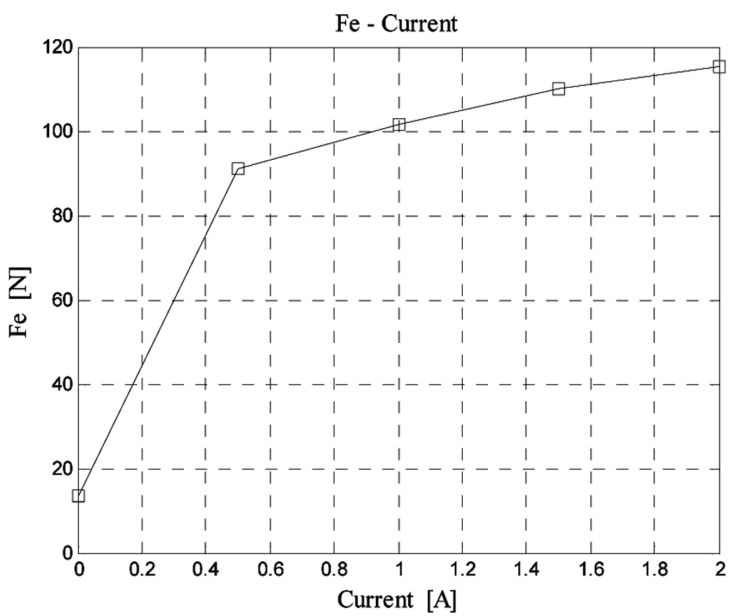

(b) $F_{e}$ vs current

Fig. $5 C_{e}$ and $F_{e}$ vs input current

Table 2 Parameters $c_{1}, c_{2}, c_{3}, c_{4}, f_{1}, f_{2}, f_{3}, f_{4}$ determined by curve fitting

\begin{tabular}{cccccccc}
\hline \hline $\begin{array}{c}c_{1} \\
(\mathrm{~N} . \mathrm{s} / \mathrm{m} . \mathrm{A})\end{array}$ & $\begin{array}{c}c_{2} \\
(\mathrm{~N} . \mathrm{s} / \mathrm{m})\end{array}$ & $\begin{array}{c}c_{3} \\
(\mathrm{~N} . \mathrm{s} / \mathrm{m} . \mathrm{A})\end{array}$ & $\begin{array}{c}c_{4} \\
(\mathrm{~N} . \mathrm{s} / \mathrm{m})\end{array}$ & $\begin{array}{c}f_{1} \\
(\mathrm{~N} / \mathrm{A})\end{array}$ & $\begin{array}{c}f_{2} \\
(\mathrm{~N})\end{array}$ & $\begin{array}{c}f_{3} \\
(\mathrm{~N} / \mathrm{A})\end{array}$ & $\begin{array}{c}f_{4} \\
(\mathrm{~N})\end{array}$ \\
\hline 21.1 & 1.4 & 13.1 & 7.8 & 155.4 & 13.4 & 16.2 & 84.3 \\
\hline
\end{tabular}

In the above equations, $C$ is the linear equivalent damping of the MR damper, $C_{e}$ and $F_{e}$ are coefficients bilinearly related to the input current as shown in Fig. 5, and $V_{\max }$ is the maximum velocity of the damper. The parameters $c_{1}, c_{2}, c_{3}, c_{4}, f_{1}, f_{2}, f_{3}, f_{4}$ could be determined by curve fitting and the values are summarized in Table 2 .

Eqs. (4)-(6) will be used to estimate the equivalent damping of the MR damper in the design of semi-active control algorithms for vibration mitigation of stay cable.

\section{State-space representation of cable-damper system}

A cable-damper system is shown in Fig. 6, where $L$ is the length of the cable, $m$ is the mass per unit length, $c$ is the uniform inherent damping of the cable, and $T$ is the cable force. The location of the damper is denoted as $x_{d}$, which is the distance from the damper to the anchorage of the cable. Assuming that the cable force is unchanged under linear oscillations, the bending stiffness is negligible, and the effects of sag and inclination are ignored, the equation of motion of a taut string can be established as follows (Johnson et al. (2007))

$$
m \ddot{v}(x, t)+c \dot{v}(x, t)-T v^{\prime \prime}(x, t)=f(x, t)+F_{d}(t) \delta\left(x-x_{d}\right)
$$

where $v(x, t), \dot{v}(x, t)$ and $\ddot{v}(x, t)$ are the displacement, velocity and acceleration of the cable respectively, $v^{\prime \prime}(x, t)$ is the second partial derivative of $v(x, t)$ with respect to $x, F_{d}(t)$ is the damping force at the damper location, $f(x, t)$ is the distributed load applied over the cable, and $\delta\left(x-x_{d}\right)$ is the $\delta$ - 


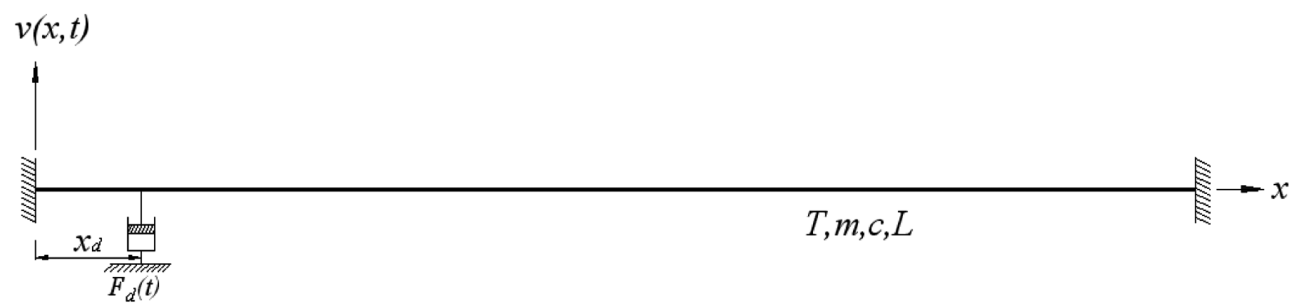

Fig. 6 Cable-damper system

dirac function.

The boundary conditions corresponding to the above equation of motion are $v(0, t)=v(L, t)=0$ for all $t, 0 \leq x \leq L$.

Assuming the series of solution to Eq. (7) are in the form of

$$
v(x, t)=\sum_{j=1}^{r} q_{j}(t) \varphi_{j}(x)
$$

where $\varphi_{i}(x)$ is the mode shape function with $\varphi_{j}(0)=0$ and $\varphi_{j}(L)=0$.

Substituting Eq. (8) into Eq. (7) using a standard Galerkin approach, and integrating along the full length of the cable, the equation of motion of the cable-damper system can be expressed as

$$
M \ddot{q}+C \dot{q}+K q=f_{q}+\varphi\left(x_{d}\right) F_{d}(t)
$$

where $q=\left[q_{j}(t)\right]$ is the generalized displacement vector, and

$$
\begin{gathered}
M=\left[m_{i j}\right], m_{i j}=m \int_{0}^{L} \varphi_{i}(x) \varphi_{j}(x) d x \\
C=\left[c_{i j}\right], c_{i j}=c \int_{0}^{L} \varphi_{i}(x) \varphi_{j}(x) d x \\
K=\left[k_{i j}\right], k_{i j}=-T \int_{0}^{L} \varphi_{j}^{\prime \prime}(x) \varphi_{i}(x) d x \\
f_{q}=\left[f_{q i}\right], f_{q i}=\int_{0}^{L} f(x, t) \varphi_{i}(x) d x
\end{gathered}
$$

Using a control oriented model proposed by Johnson et al. (2007), the mode shape functions are

$$
\varphi_{0}(x)=\left\{\begin{array}{lc}
x / x_{d} & 0 \leq x \leq x_{d} \\
(L-x) /\left(L-x_{d}\right) & x_{d} \leq x \leq L
\end{array} ; \varphi_{j}(x)=\sin (j \pi x / L)\right.
$$

and the mass, stiffness and damping of the cable are expressed as

$$
m_{i j}= \begin{cases}\frac{m L}{2} \delta_{i j} & 0>i<r, 0<j<r \\ \frac{m L}{3} & i=0, j=0 \\ \frac{m L^{3} \sin \left(k x_{d} \pi / L\right)}{x_{d}(\pi k)^{2}\left(L-x_{d}\right)}, & \text { others }, k=\max (i, j)\end{cases}
$$




$$
k_{i j}=\left\{\begin{array}{l}
\frac{T \pi^{2}}{2 L} i^{2} \delta_{i j} \quad 0<i<r, 0<j<r \\
\frac{L T}{x_{d}\left(L-x_{d}\right)} \quad i=0, j=0 \\
\frac{T L \sin \left(k x_{d} \pi / L\right)}{x_{d}\left(L-x_{d}\right)}, \quad \text { others }, k=\max (i, j) \\
\quad C=(c / m) M
\end{array}\right.
$$
Introducing a state vector $Z=\left[\begin{array}{c}q \\ \dot{q}\end{array}\right]$, Eq. (9) can be transformed into the state-space representation of the
cable-damper system as

$$
\dot{Z}(t)=A Z(t)+G F_{d}+B f_{q}(t) \quad Z\left(t_{0}\right)=0
$$

where

$$
A=\left[\begin{array}{cc}
0 & I \\
-M^{-1} K & -M^{-1} C
\end{array}\right], \quad B=\left[\begin{array}{c}
0 \\
M^{-1}
\end{array}\right], G=\left[\begin{array}{c}
0 \\
M^{-1} \varphi\left(x_{d}\right)
\end{array}\right]
$$

\section{Semi-active control algorithm}

The semi-active control algorithm for mitigating cable vibrations using MR damper is illustrated by the flow chart shown in Fig. 7.

Expressing the control force or the damping force of MR damper as

$$
F_{d}(t)=-L Z(t)
$$

where $L$ is the feedback gain matrix. Substituting Eq. (20) into Eq. (18), one obtains the state-space equation of the cable-damper system as

$$
\dot{Z}(t)=(A-G L) Z(t)+B f_{q}(t)
$$

Based on the model of linear damper, the damping force can be written as the product of damping coefficient and velocity, and if the damping force of MR damper in Eq. (20) is represented as the optimal damping force, the following relation can be obtained

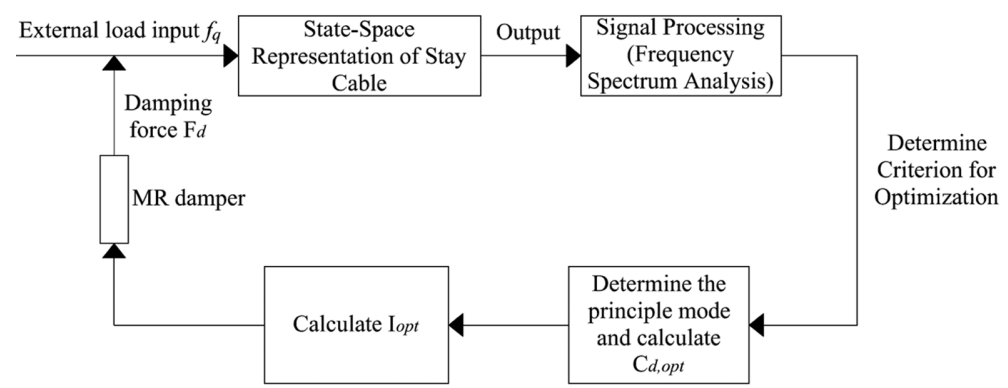

Fig. 7 Flow chart of the control algorithm 


$$
F_{d}(t)=F_{d, o p t}=C_{d, o p t} \dot{v}\left(x_{d}, t\right)
$$

From Eq. (8), the velocity of cable at damper location can be represented as

$$
\dot{v}\left(x_{d}, t\right)=\varphi^{T}\left(x_{d}\right) \dot{q}
$$

where $\varphi\left(x_{d}\right)=\left[\varphi_{1}\left(x_{d}\right), \varphi_{2}\left(x_{d}\right), \ldots \varphi_{r}\left(x_{d}\right)\right]^{T}$ is the mode shape function at the damper location $x_{d}$. Eq. (22) can be written as

$$
F_{d}(t)=\left[\begin{array}{ll}
0 & C_{d, o p t} \varphi^{T}\left(x_{d}\right)
\end{array}\right]\left[\begin{array}{c}
q \\
\dot{q}
\end{array}\right]
$$

Comparing Eqs. (20) and (24), it can be shown that the feedback gain for optimal control is

$$
L=-\left[\begin{array}{ll}
0 & C_{d, o p t} \\
\varphi^{T}\left(x_{d}\right)
\end{array}\right]
$$

where $C_{d, \text { opt }}$ is the optimal linear equivalent damping of the MR damper, which can be determined using the Universal Damping Curve for linear dampers (Krenk (2000)) as shown in Fig. 8. Horizontal axis is the dimensionless damping coefficient of damper represented as

$$
k=\frac{i C_{d}\left(x_{d} / L\right)}{m L \omega_{1}}
$$

where $C_{d}$ is the linear damping coefficient of damper, $\omega_{1}$ is the $1^{\text {st }}$ natural angular frequency of the cable, and $i$ represents the $i^{\text {th }}$ vibration mode, and vertical axis is the ratio between the damping ratio of cable $\xi_{j}$ and the relative installation position of damper $x_{d} / L$, which can be approximately represented as

$$
\frac{\xi_{i}}{x_{d} / L} \cong \frac{\pi^{2} \kappa}{\left(\pi^{2} \kappa\right)^{2}+1}
$$

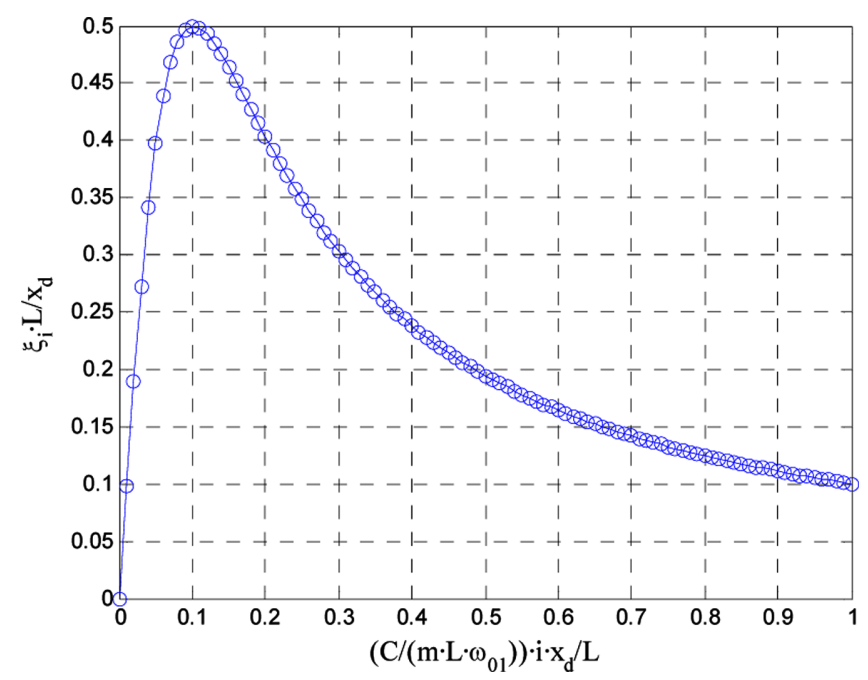

Fig. 8 Universal damping curve 
When the cable achieves the maximum damping ratio, one has

$$
\frac{\xi_{i}}{x_{d} / L}=0.5
$$

The value of $k$ can be obtained from Eqs. (27) and (28) as

$$
k=\frac{1}{\pi^{2}}
$$

and the corresponding optimal damping coefficient of the damper can be calculated from Eqs. (26) and (29) as

$$
C_{d, o p t}=\frac{m L \omega_{1}}{i \pi^{2}\left(x_{d} / L\right)}
$$

For the optimal tuning of MR damper, $i$ is chosen as the dominant or principle vibration mode which can be identified by signal processing the displacement response using the following equation

$$
i=\operatorname{index}\left\{\max \left|q_{j}(t)\right|\right\}
$$

where $q_{j}(t)$ is the modal displacement of $j^{\text {th }}$ mode, and $i n d e x()$ is a function which returns the subscript of a selected element in a vector.

After determining the optimal damping coefficient $C_{d, o p t}$, the optimal input current $I_{\text {opt }}$ for MR damper can be obtained using Eqs. (4)-(6).

\section{Numerical studies}

Numerical simulation has been carried out to study the performance of MR damper for mitigating the vibration of stay cable. The finite element model of the cable was established based on the cable used in a full-scale test presented in Huang et al. (2009), where the cable parameters are summarized in Table 3. The inherent damping ratio of the cable is assumed to be approximately $0.1 \%$. Using the state-space representation of cable-damper system shown in session 3, the semi-active control algorithm proposed in session 4 was applied to compute the optimal damping of the cable-damper system, and consequently, obtain the corresponding optimal input current for the MR damper. Three different patterns of cable vibration were considered, including free vibration, forced vibration induced by sinusoidal loads and white noise excitation. The total length of vibration recorded was 120 seconds, and the sampling frequency was $100 \mathrm{~Hz}$.

\subsection{Free vibration}

Free vibration was generated by first applying a harmonic load to the cable and then removing it after 5 seconds. The cable was undergoing single mode vibration, and the first three modes were

Table 3 Parameters of stay cable

\begin{tabular}{cccccc}
\hline \hline$L(m)$ & $m(\mathrm{~kg} / \mathrm{m})$ & $c\left(N \cdot s / \mathrm{m}^{2}\right)$ & $T(\mathrm{kN})$ & $x_{d}(\mathrm{~m})$ & $f_{0}(\mathrm{~Hz})$ \\
\hline 95 & 60.19 & 0.53 & 1663.6 & 2.2 & 0.875 \\
\hline
\end{tabular}


considered. For each mode of vibration, the harmonic load was applied at positions $L / 2, L / 4$ and $L / 6$ of the cable respectively, with frequency matches the corresponding natural frequency of the cable.

The semi-active control algorithm proposed in session 4 was used to compute the optimal damping of the cable-damper system according to the mode of vibration generated. For $1^{\text {st }}$ mode vibration, Eq. (31) first returned the value of 1 after signal processing the measured displacement response, then Eq. (30) computed the optimal linear equivalent damping of the MR damper corresponding to the maximum cable damping for $1^{\text {st }}$ mode vibration, and finally the optimal input current for the MR damper was obtained through Eqs. (4)-(6) as $0.3 \mathrm{~A}$. For $2^{\text {nd }}$ and $3^{\text {rd }}$ mode vibration, similar computational process was carried out, except that Eq. (31) returned the value of 2 and 3 and the optimal input current for the MR damper were $0.6 \mathrm{~A}$ and $0.9 \mathrm{~A}$, respectively.

The displacements of the cable at $L / 2, L / 4$ and $L / 6$ of the cable and at the damper location were measured for each mode of vibration, with and without the installation of optimally tuned MR damper. The time history of the displacement responses from 0-40 seconds at measured locations and the corresponding power spectrums were shown in Figs. 9-11, where the solid line and the dotted line represented the measured data before and after installing the optimally tuned MR damper respectively. It can be seen from Figs. 9-11 that with the installation of the MR damper which was optimally tuned using the proposed semi-active algorithm, the vibration of the stay cable was significantly reduced.
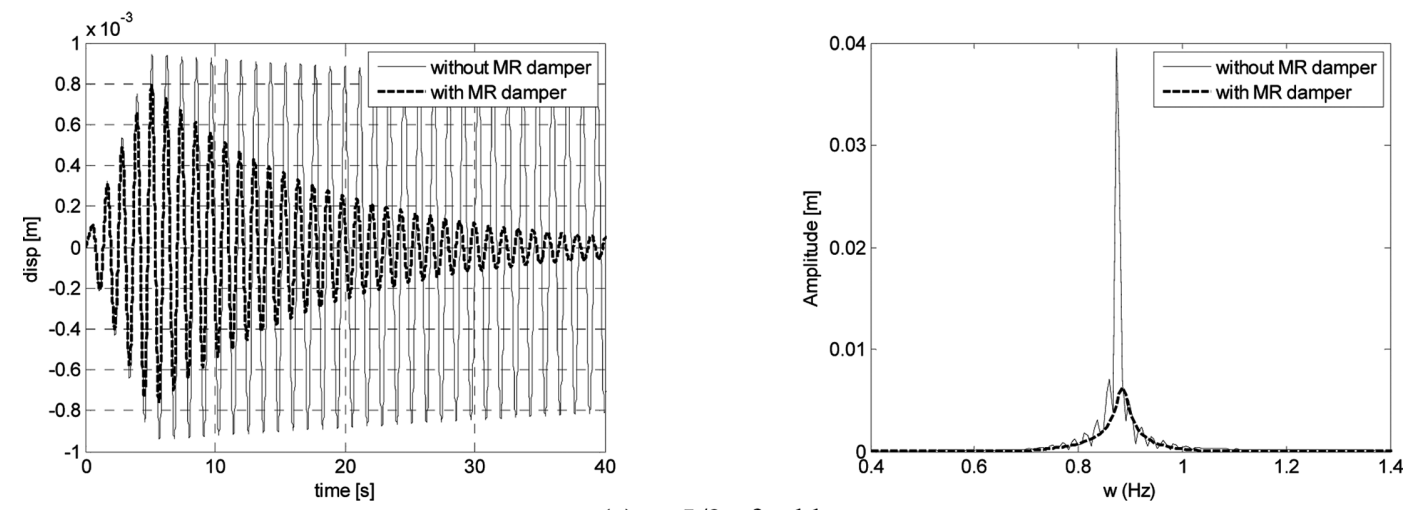

(a) at $L / 2$ of cable
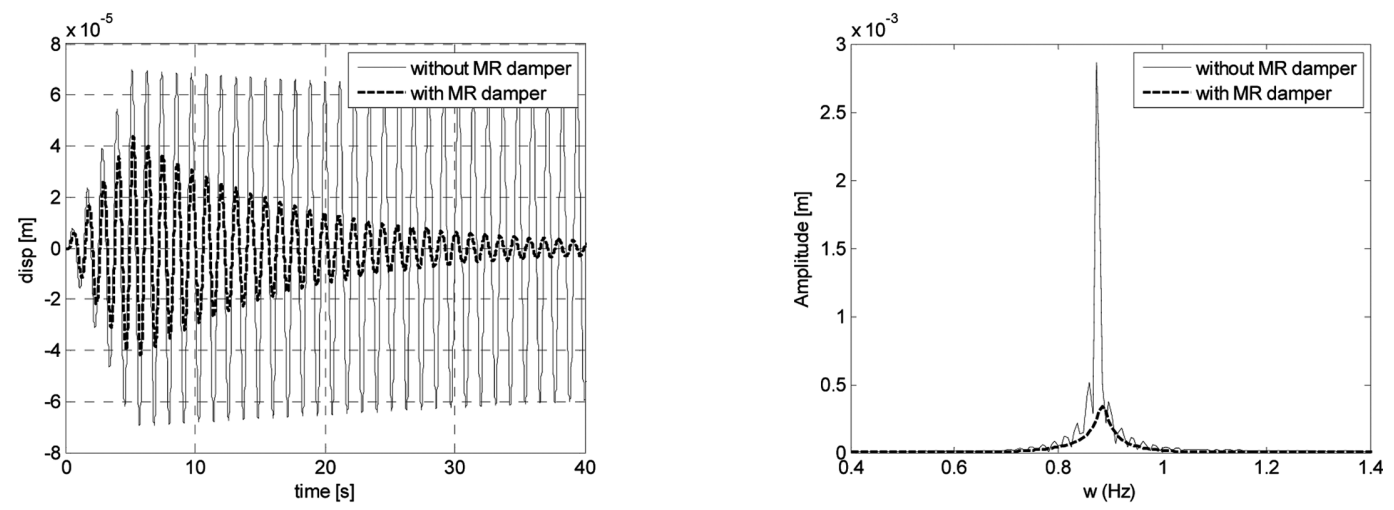

(b) at damper location $x_{d}$

Fig. 9 Time history and power spectrum of displacement response of $1^{\text {st }}$ mode cable vibration 

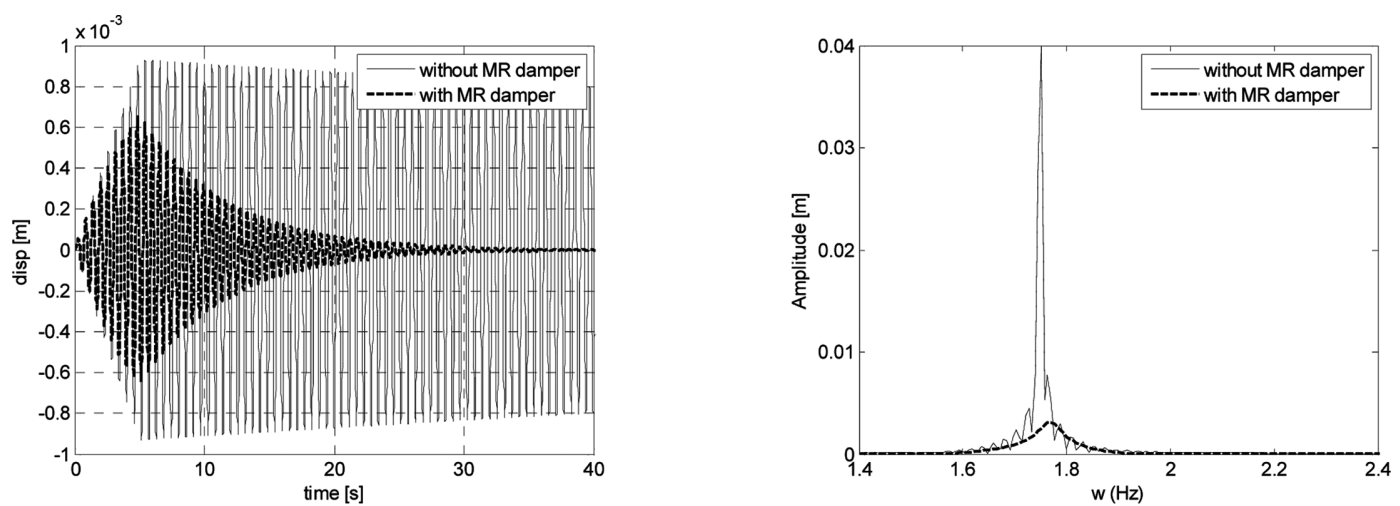

(a) at $L / 4$ of cable
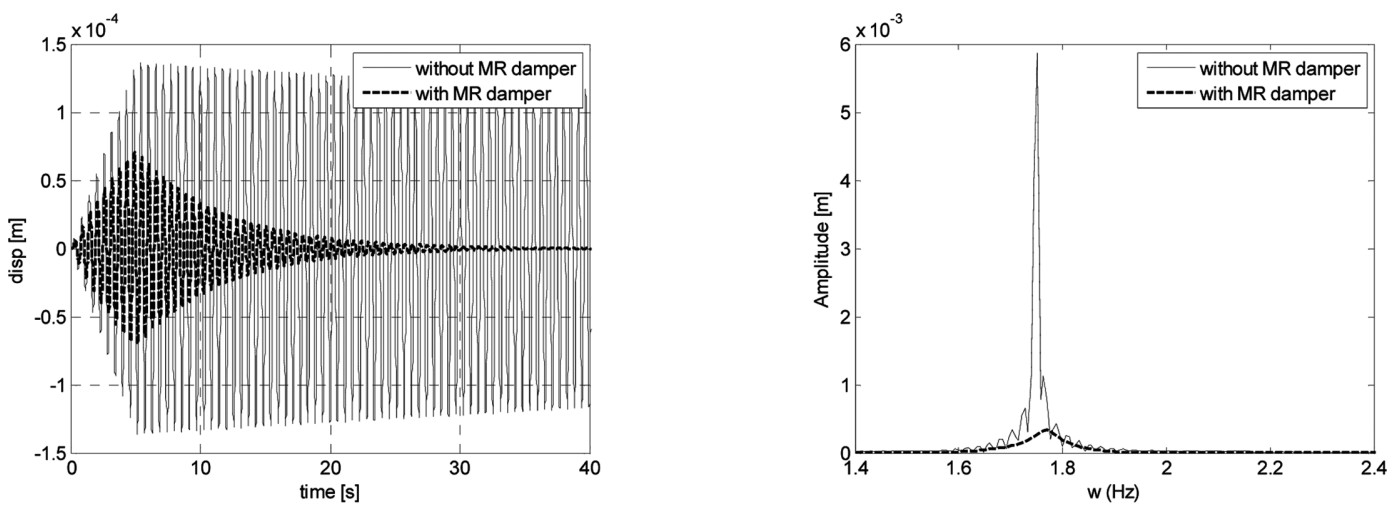

(b) at damper location $x_{d}$

Fig. 10 Time history and power spectrum of displacement response of $2^{\text {nd }}$ mode cable vibration

\subsection{Sinusoidal excitation}

In the previous session, only single mode of cable vibration was generated and the principle mode does not change throughout the vibration period. In this case, the MR damper had just to be tuned once and was working as a passive-on damper. In order to further demonstrate the application of semi-active control algorithm proposed in session 4, an artificial case of cable vibration was created by simulation, where the cable was excited by three different sinusoidal loads sequentially in order to generate different principle vibration modes at different vibration periods. In the first 20 seconds, the sinusoidal load with frequency equals to the $1^{\text {st }}$ natural frequency of the cable was applied at the mid-span. Then, in the second 20 seconds period, the sinusoidal load with frequency equals to the $2^{\text {nd }}$ natural frequency of the cable was applied at positions $L / 4$ of the cable with magnitude twice as that in the first 20 seconds. Finally, in the last 20 seconds period, the sinusoidal load with frequency equals to the $3^{\text {rd }}$ natural frequency of the cable was applied at positions $L / 6$ of the cable with magnitude thrice as that in the first 20 seconds. Under such arrangement of excitations, the cable was undergoing multi modes of vibration, where the principle vibration mode in the first 20 seconds was the $1^{\text {st }}$ mode, while in the second and last 20 seconds of vibration period was the $2^{\text {nd }}$ and the $3^{\text {rd }}$ mode respectively. 

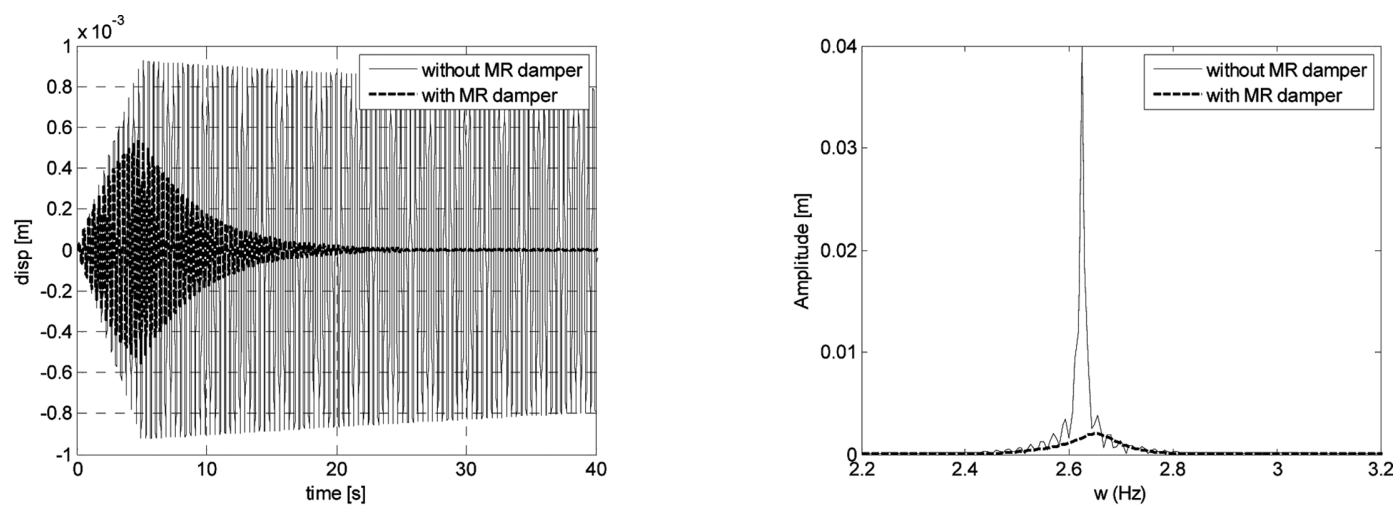

(a) at $L / 6$ of cable
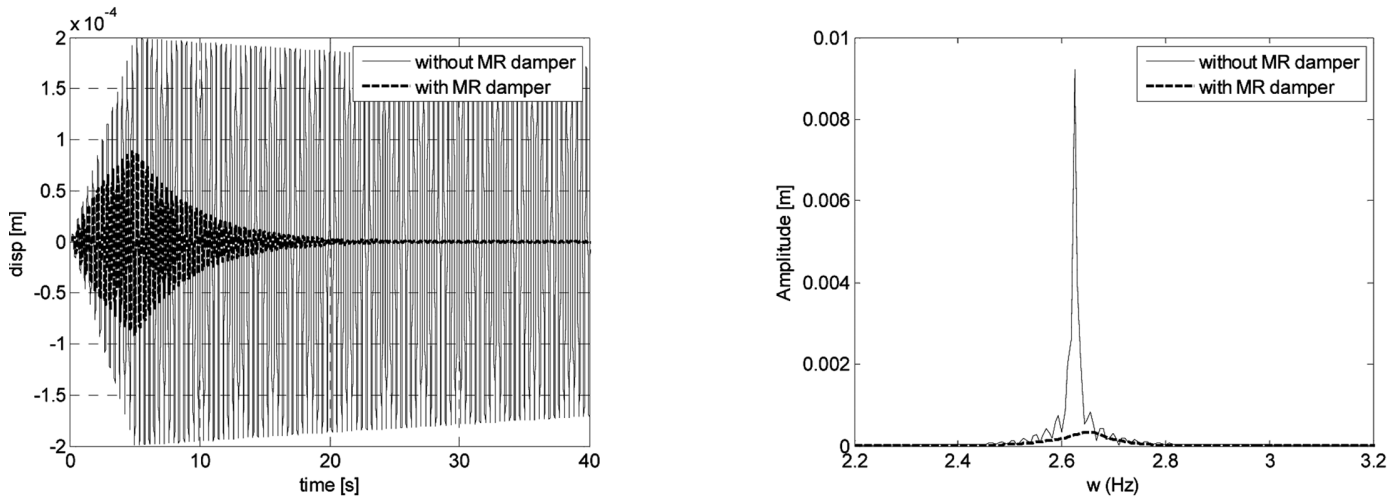

(b) at damper location $x_{d}$

Fig. 11 Time history and power spectrum of displacement response of $3^{\text {rd }}$ mode cable vibration

Using the semi-active control algorithm proposed in session 4, the optimal damping of the cable-damper system was computed based on Eqs. (30) and (31). According to the principle vibration mode generated at each 20 seconds period, Eq. (31) returned the value of 1 from 0-20 seconds, 2 from 20-40 seconds and 3 from 40-60 seconds, respectively. Then Eq. (30) computed the optimal linear equivalent damping of the MR damper corresponding to the maximum cable damping for the principle mode vibration. Finally the optimal input current of the MR damper for each vibration period was obtained by Eqs. (4)-(6), which was $1.2 \mathrm{~A}$ for the first period and $2 \mathrm{~A}$ for the last two periods. This was because the computed input current in the last two periods exceeded the maximum working current of the MR damper, the maximum working current of $2 \mathrm{~A}$ was used.

The displacements at $L / 2, L / 4$ and $L / 6$ of the cable and at the damper location were measured, with and without the installation of optimally tuned MR damper. Due to the space limitation, only the time history of the displacement responses at the damper location and the corresponding power spectrums at each 20 seconds vibration period were presented in Fig. 12, where the solid line and the dotted line represented the measured data before and after installing the optimally tuned MR damper respectively. It can be seen from Fig. 12 that the vibration of the stay cable was significantly reduced with the installation of the MR damper which was optimally tuned using the proposed semi-active algorithm. 


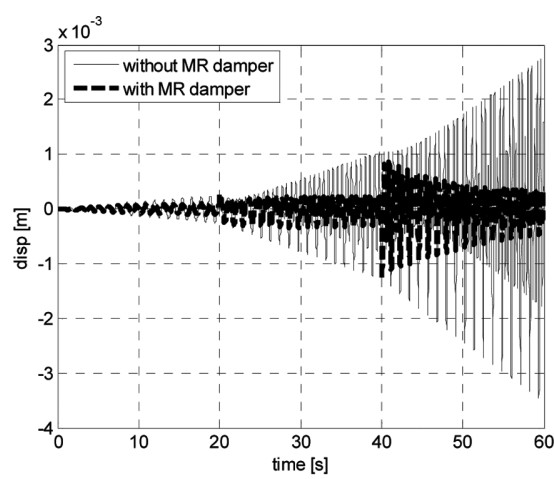

(a) displacement at damper location $x_{d}$

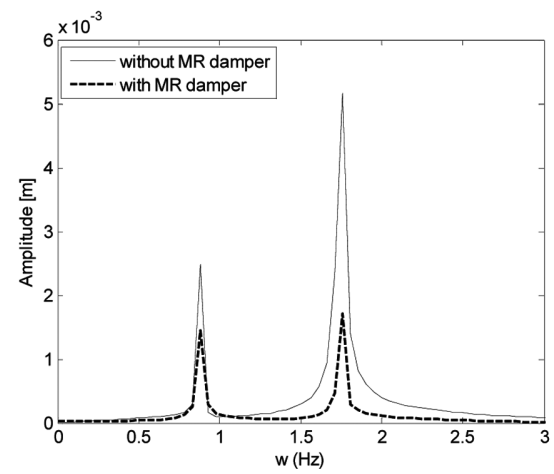

(c) power spectrum for second 20 seconds

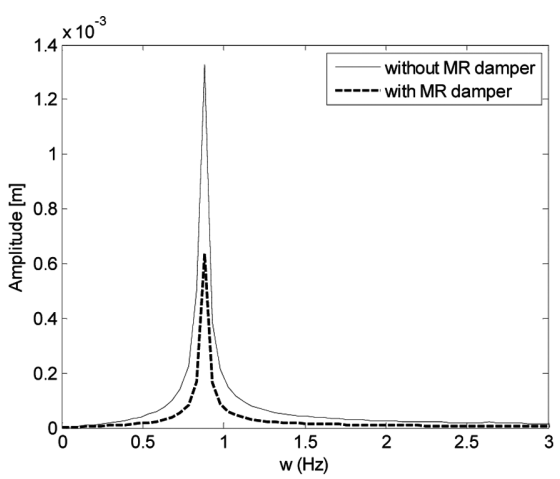

(b) power spectrum for first 20 seconds

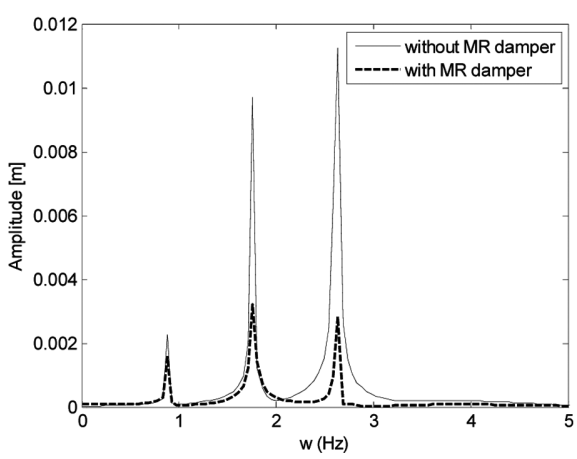

(d) power spectrum for last 20 seconds

Fig. 12 Time history and power spectrum of displacement response of $1^{\text {st }}$ mode cable vibration

\subsection{White noise excitation}

Although the numerical example presented in session 5.2 studied the case of multi modes cable vibration, the external excitations were created artificially and solely for illustration purpose, and the resulting vibration patterns usually will not be observed in practice. In order to study a more general

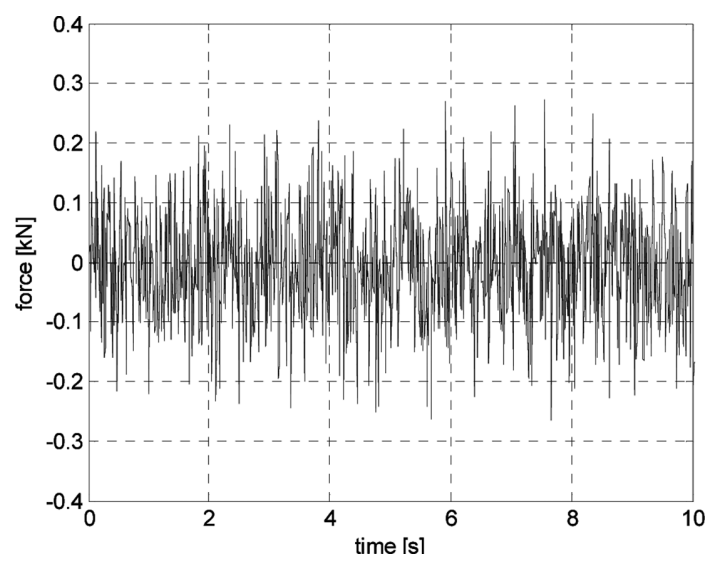

Fig. 13 Time history of input Gaussian white noise excitation 

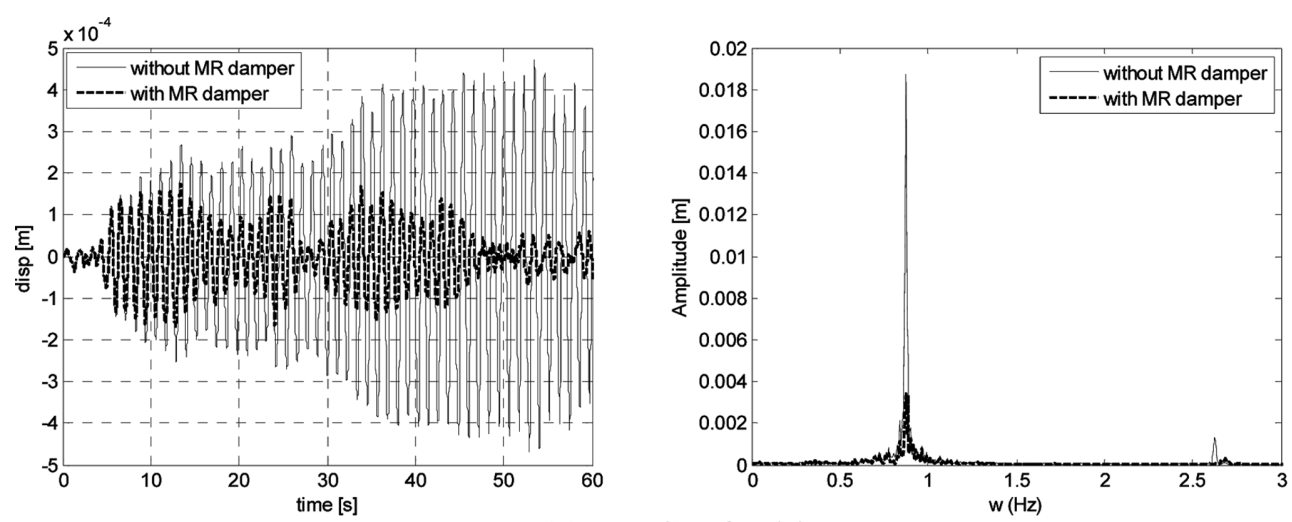

(a) at $L / 2$ of cable
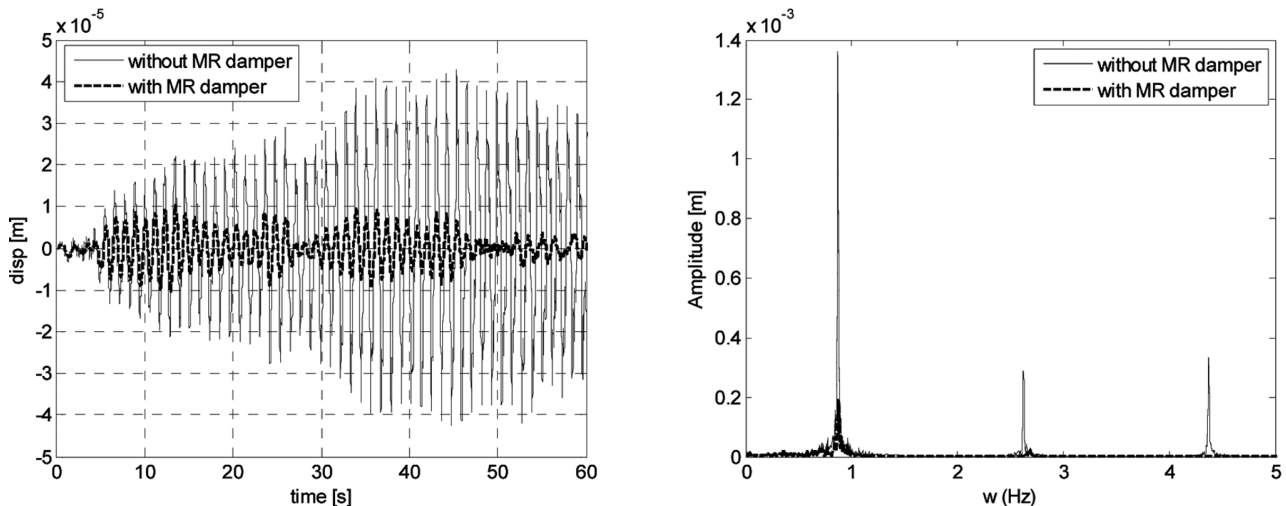

(a) at damper location $x_{d}$

Fig. 14 Time history and power spectrum of displacement response

case of cable vibration which is often induced by random excitations such as wind loads, a Gaussian white noise excitation was applied over the full length of the cable to excite multi modes of cable vibration. The time history of the input force is shown in Fig. 13.

Applying the proposed semi-active control algorithm, the principal mode of vibration was first identified through signal processing using Eq. (31), then the optimal linear equivalent damping of the MR damper corresponding to the maximum cable damping for the principal mode of vibration was computed using Eq. (30), and finally the optimal input current for the MR damper was obtained with the value of $0.5 \mathrm{~A}$ using Eqs. (4)-(6).

Similar to the previous numerical examples, the displacements of the cable at both the mid-span and the damper location were measured, with and without the optimally designed MR damper The time history of the displacement responses from 0-60 seconds at measured locations and the corresponding power spectrums were shown in Fig. 14, where the solid line and the dotted line represented the measured data before and after installing the optimally tuned MR damper respectively. It is observed from Fig. 14 that in the case of forced vibration, with the installation of the MR damper which was optimally tuned using the proposed semi-active algorithm, the vibration energy of the cable is significantly reduced for each vibration mode. The time history of the damper force was shown in Fig. 15. 


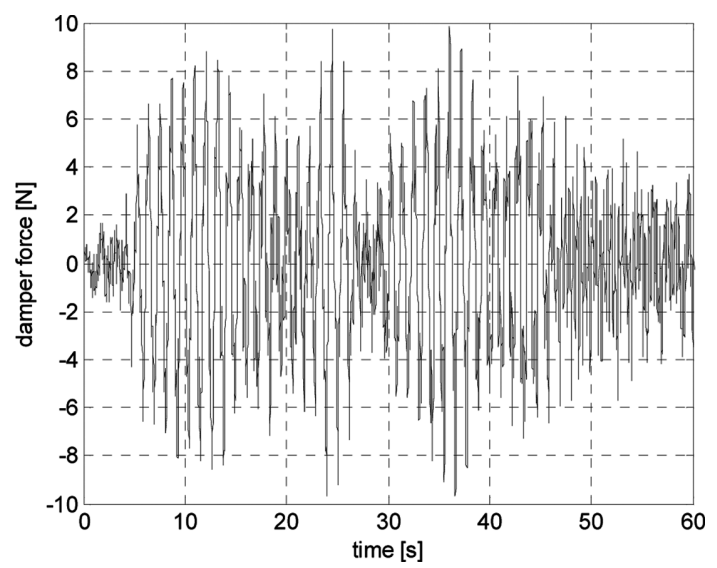

Fig. 15 Time history of damper force

Table 4 Comparison of rms value of displacement (mm)

\begin{tabular}{cccc}
\hline \hline & without MR damper & with MR damper & \% reduction \\
\hline mid span & $5.64 \mathrm{E}-2$ & $4.59 \mathrm{E}-3$ & $92 \%$ \\
damper location & $3.40 \mathrm{E}-4$ & $1.42 \mathrm{E}-5$ & $96 \%$ \\
\hline
\end{tabular}

The performance of the MR damper can also be shown by comparing the rms (root mean square) value of the displacement response, before and after installing the optimally tuned MR damper, as summarized in Table 4. It shows that with the installed optimally tuned MR damper, the vibration of the stay cable was reduced substantially.

It can be seen from Fig. 14 that the principal mode of vibration of the cable under the given Gaussian white noise excitation was the first mode. Thus, the linearly equivalent damping of MR damper was tuned according to the optimal $1^{\text {st }}$ mode of vibration. However, the figure showed that other modes, such as the $2^{\text {nd }}$ and the $3^{\text {rd }}$ mode, of vibration were also significantly suppressed with the MR damper optimally tuned based on the $1^{\text {st }}$ mode. The effectiveness of MR damper in mitigating multi modes of cable vibration when it is tuned based solely on the principal vibration mode will be examined theoretically in next session.

\section{Control of multimode vibration}

From the Universal Damping Curve for linear dampers, represented by Fig. 8 and Eq. (27), if $i^{\text {th }}$ mode is the principle vibration mode of the cable, the dimensionless linear equivalent damping of the MR damper when optimally tuned to the $i^{\text {th }}$ mode can be written as in Eq. (29), where the cable achieves the maximum damping ratio for $i^{\text {th }}$ mode of vibration as $\frac{\xi_{i}}{x_{d} / L}=0.5$.

Let $\alpha=\frac{x_{d} / L}{m L \omega_{1}}$, the corresponding optimal linear equivalent damping of the MR damper can be obtained as

$$
C_{d, o p t}^{i}=\frac{1}{i \pi^{2} \alpha}
$$


For the $j^{\text {th }}$ mode of vibration, with the damping coefficient of damper given in Eq. (32), the dimensionless damping coefficient corresponding to the $j^{\text {th }}$ mode becomes

$$
k_{j}=\alpha j C_{d, o p t}^{i}=\frac{j}{i}\left(\frac{1}{\pi^{2}}\right)
$$

Substituting Eq. (33) into Eq. (27), the damping ratio of cable corresponding to $j^{\text {th }}$ mode of vibration, with the MR damper optimally tuned to the $i$ th mode, can be obtained as

$$
\frac{\xi_{j}}{x_{d} / L}=\frac{1}{\frac{j}{i}+\frac{i}{j}}
$$

Let $\beta=\frac{j}{i}$, the above equation can be written as

$$
\frac{\xi_{j}}{x_{d} / L}=\frac{1}{\beta+\frac{1}{\beta}}
$$

and the relation between $\frac{\xi_{j}}{x_{d} / L}$ and $\beta$ is illustrated in Fig. 16.

It can be seen from Fig. 16 that when $\beta$ either increases from the value of 1 or decreases from 1 , i.e., when the $j^{\text {th }}$ mode moves further away from the $i$ th mode, the damping ratio of cable corresponding to the $j^{\text {th }}$ mode of vibration reduces gradually from the value of 0.5 , where the MR damper is optimally tuned to the $i$ th mode.

For example, if the $1^{\text {st }}$ mode of vibration is the principle mode which contains most of the vibration energy, the MR damper will be tuned so that the cable achieves the maximum achievable $1^{\text {st }}$ mode damping, i.e., $\frac{\xi_{1}}{x_{d} / L}=0.5$. Then for the $2^{\text {nd }}$ and $3^{\text {rd }}$ mode of vibration, from Eq. (35) we have $\frac{\xi_{2}}{x_{d} / L}=0.4$ and $\frac{\xi_{3}}{x_{d} / L}=0.3$ respectively, where the cable achieves $80 \%$ and $60 \%$ of the maximum

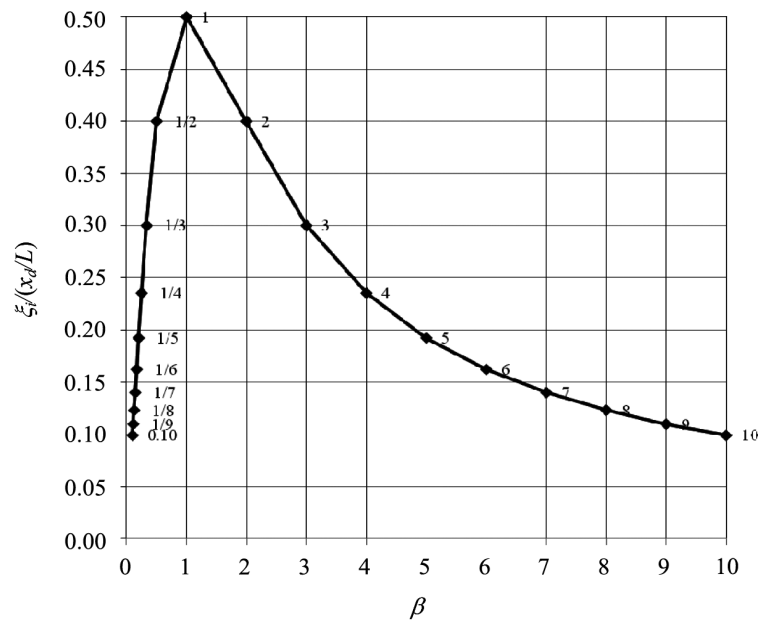

Fig. 16 Relation between the maximum damping of cable and modes of vibration 
Table 5 Comparison of amplitudes of displacement power spectrum (m)

\begin{tabular}{cccc}
\hline \hline$\beta$ & $\begin{array}{c}\text { without MR } \\
\text { damper }\end{array}$ & with MR damper $\begin{array}{c}\text { Reduction in amplitude } \\
\text { (ratio between } 2^{\text {nd }} \text { and } 3^{\text {rd }} \text { columns) }\end{array}$ \\
\hline 1 & 0.0395 & 0.0063 & 6.3 \\
2 & 0.0395 & 0.0083 & 4.8 \\
3 & 0.0395 & 0.0105 & 3.8 \\
\hline
\end{tabular}

achievable $2^{\text {nd }}$ and $3^{\text {rd }}$ mode damping respectively. This can be further illustrated by running again the numerical example of $1^{\text {st }}$ mode free vibration when the MR damper was tuned to the $2^{\text {nd }}$ mode where $\beta=2$ and the $3^{\text {rd }}$ mode where $\beta=3$, respectively. The amplitudes of power spectrums of displacement responses at the mid-span of cable for the cases of $\beta=1,2$ and 3 were summarized and compared in Table 5. It can be seen from Table 5 that when the MR damper was tuned according to the $2^{\text {nd }}$ and the $3^{\text {rd }}$ mode of vibration, i.e., $\beta=2$ and 3 , while the actual principle vibration mode was the $1^{\text {st }}$ mode, the reduction in vibration energy was about $76 \%$ and $60 \%$ compared to the case of $\beta=1$. This agreed with the theoretical analysis presented above in Eq. (35) and shown in Fig. 16. Other higher mode damping can be evaluated through the similar way.

It has been observed in practice that the stay cable of bridges is more prompt to lower modes of vibration and the vibration energy usually contained in a few adjacent modes. Therefore, by optimally tuning the MR damper based solely on the principal vibration mode using the proposed semi-active control algorithm, the vibration energy of adjacent modes can be effectively suppressed as well, and consequently, multi modes of cable vibration will be mitigated significantly.

\section{Conclusions}

This paper studied the optimal damping performance of the cable-MR damper system and investigated the effectiveness of the MR damper as a semi-active control device for the vibration mitigation of stay cable. The mathematical model of the MR damper was first obtained through a performance test, and the relation between the damping parameters and the input current was established. Then, an efficient semi-active control strategy was derived, where the damping of MR damper was tuned according to the principle mode of vibration of stay cable, in order to achieve maximum damping for the cable. Simulation study was carried out to verify the semiactive control algorithm proposed for suppressing the cable vibrations induced by different loading patterns using optimally tuned MR damper. It was shown that in both cases of free and forced vibrations, with the installation of the MR damper which was optimally tuned using the proposed semi-active algorithm, the vibration of the stay cable was reduced substantially. Finally, the effectiveness of MR damper in mitigating multi modes of cable vibration was examined theoretically, and it showed that by optimally tuning the MR damper using the proposed semiactive control algorithm, multi modes of cable vibration can be mitigated significantly. Experimental studies and field tests shall be carried out in the future to verify the proposed semiactive control algorithm. 


\section{Acknowledgments}

This research is supported by the Ministry of Science and Technology of China, Grant No. SLDRCE09-B-14. The authors would also like to express their sincere appreciations to Prof. Jubin Chen from Shanghai Jiaotong University for their helps on the experiments.

\section{References}

Chen, Z.Q., Ni, Y.Q. and Gao, Z.M. (2001), "Application of MR damper for mitigating wind-rain induced cable vibration of cable-stayed bridge", Proceedings of the 10th China Wind Engineering Conference, Guilin, China. (in Chinese)

Duan, Y.F., Ni, Y.Q. and Ko, J.M. (2006), "Cable vibration control using magnetorheological dampers", J. Intel. Mat. Syst. Str.., 17(4), 321-325.

Huang, H.W., Jiang, X.L., Sun, L.M. and Cheng, W. (2009), "Experimental study of MR damper for vibration mitigation of stay cable", , Proceedings of the 8th International Symposium on Cable Dynamics, AIM, on CD.

Johnson, E.A. Baker, G.A., Spencer Jr. B.F. and Fujino, Y. (2007), "Semiactive damping of stay cables", J. Eng. Mech.-ASCE, 133(1), 1-11.

Krenk, S. (2000), "Vibration of a taut cable with an external damper", J. Appl. Mech.-T-ASME., 67(4), 772-776.

Li, H., Liu, M., Li, J.H., Guan, X.C. and Ou, J.P. (2007), "Vibration control of stay cables of the shandong binzhou yellow river highway bridge using magnetorheological fluid dampers", J. Bridge Eng.-ASCE, 12(4), 401-409.

Liu, M., Li, H., Li, J.H., Guan X.C. and Ou, J.P. (2006), "Experimental investigation on vibration control of one stay cable using one magnetorheological fluid damper", Proceedings of the SPIE: Smart Structures and Materials, San Diego, CA, on CD.

Wang, X.Y., Chen, Z.Q., Ni, Y.Q. and Gao, Z.M. (2003), "Vibration control of stay cable using MR damper", China J. Highway Transport, 16(2), 52-56. (in Chinese)

Weber, F., Distl, H., Feltrin, G. and Motavalli, G. (2005), "Simplified approach of velocity feedback for MR dampers on real cable-stayed bridges", Proceedings of the 6th International Symposium on Cable Dynamics, AIM, on CD.

Weber, F., Fobo, W. and Distl, H. (2007a), "Damping of several single mode vibrations with linear viscous dampers", Proceedings of the IABSE Conference, Weimar, on CD.

Weber, F., Distl, H. and Feltrin, G. (2007b), "Damping of stay cables by controlled friction type dampers", Proceedings of the IABSE Conference, Weimar, on CD.

Weber, F., Distl, H., Huber, P., Nutzel, O. and Motavalli, M. (2007c), "Design, implementation and field test on the adaptive damping system of the Franjo Tudjman Bridge nearby Dubrovnik, Croatia", Proceedings of the IABSE Conference, Weimar, on CD.

Wu, Z.H., Lou, W.J., Chen, Y., Chen, Y.Y., Tang, J.C. and Sun, B.N. (2004), "Simplified model of MR damper and its application", J. Disaster Prevent. Mitigation Eng., 24(2), 210-213. (in Chinese)

Wu, W.J. and Cai, C.S. (2006), "Experimental study of magnetorheological dampers and application to cable vibration control", J. Vib. Control., 12(1), 67-82.

$C C$ 